\title{
Controlled study of preschool development after surgery for congenital heart disease
}

\author{
Jo Wray, Tom Sensky
}

\begin{abstract}
Aim-Research into intellectual impairment among children with congenital heart disease has focused mainly on older children. This study was designed to determine whether previous findings are applicable to preschool children.

Methods-Three groups of children under $31 / 2$ years old were assessed immediately before treatment and 12 months later: a group with congenital heart disease awaiting surgery, another awaiting bone marrow transplantation, and a healthy comparison group.

Results-Although the means of the three groups were within the normal range, preoperatively the cardiac and transplant groups showed deficits compared with the healthy controls. Postoperatively, continuing developmental deficits were significant only in the children with cyanotic lesions.

Conclusions-Conclusions about intellectual development in older children with congenital heart disease do not apply to preschool children. Before corrective surgery, chronic illness itself appears to be the predominant influence on development. Postoperatively, cyanotic and acyanotic lesions are associated with different short term outcomes.

(Arch Dis Child 1999;80:511-516)
\end{abstract}

Keywords: congenital heart disease; cardiac surgery; development

Intellectual development is likely to be compromised in some children who develop chronic illness early in life, ${ }^{1-5}$ and developmental delay has been recognised in infants with congenital heart disease as early as two months of age, ${ }^{6}$ with potential signs of developmental problems being detectable even earlier. ${ }^{7} \mathrm{Im}$ paired central nervous system functioning ${ }^{8}$ and developmental and cognitive impairment have been widely reported in children with congenital heart disease, particularly those with cyanotic lesions. ${ }^{9-16}$ Feeding problems, resulting in failure to thrive, are common in infants and young children with congenital heart disease, and can result in impaired development and intellect. ${ }^{17-20}$

Surgical intervention for congenital heart disease can result in significant increases in IQ scores, particularly among older children, ${ }^{21}$ and more especially in those children with cyanotic lesions. ${ }^{22}$ However, even after correction of cyanotic lesions, considerable neurodevelopmental and cognitive deficits may remain. ${ }^{23}{ }^{24}$
There is some evidence that postponing the repair of cyanotic lesions is associated with progressive impairment in cognitive functioning. ${ }^{131425}$ In children with acyanotic lesions, in contrast, no relation has been found between age at surgery and cognitive impairment. ${ }^{13} 14$

Previously published studies have had three major limitations. First, they have focused mainly on older children, and it is unclear to what extent their findings might apply to children less than 3 years old. Second, with few exceptions, studies have been uncontrolled. Third, most studies have had a retrospective or cross sectional design, hence limiting the causal inferences that can be drawn from their results.

Our study, focusing on children under $31 / 2$ years old, was designed to overcome these limitations. To our knowledge, this is the first prospective study of developmental and cognitive functioning in younger children with congenital heart disease, and also includes two comparison groups, one of children undergoing bone marrow transplantation and another group of healthy children. We aimed to test the following hypotheses, based on the existing literature.

- Young children (less than 31/2 years old) with congenital heart disease will demonstrate cognitive and developmental impairment relative to healthy children and to children awaiting bone marrow transplantation

- Preoperatively, children with cyanotic lesions will show a greater degree of cognitive and developmental impairment than those with acyanotic lesions

- Corrective surgery will result in a greater improvement in cognitive and developmental functioning in children with cyanotic lesions compared with those with acyanotic lesions

- For children with cyanotic defects, cognitive and developmental impairment will be positively correlated with age at time of repair, but no such association will be found for children with acyanotic lesions.

\section{Methods}

SAMPLE

All the children in our study were aged 0-3.5 years, and we excluded any with known mental handicap. The cardiac group comprised a consecutive series of children admitted for elective surgery recruited from three specialist units in London, UK over a period of two years. The transplant group was made up of a consecutive series of children recruited over 33 months from four specialist units. The healthy group was recruited from two London health centres. 
Table 1 Characteristics of the sample

\begin{tabular}{llll}
\hline & CHD & BMT & Healthy \\
\hline Age (years) & & & \\
$\quad$ Range & $0.2-3.4$ & $0.3-3.4$ & $0.3-3.5$ \\
Mean & 1.5 & 1.8 & 1.9 \\
SD & 0.9 & 1.1 & 1.1 \\
Sex & & & \\
$\quad$ Boys & 15 & 9 & 9 \\
$\quad$ Girls & 10 & 6 & 6 \\
Socioeconomic status & & & \\
$\quad$ Non-manual & $12(48 \%)$ & $6(40 \%)$ & $6(40 \%)$ \\
$\quad$ Manual & $13(52 \%)$ & $9(60 \%)$ & $9(60 \%)$ \\
\hline
\end{tabular}

$\mathrm{CHD}$, congenital heart disease; BMT, bone marrow transplantation.

The cardiac group comprised 25 children, although one child with a cyanotic lesion was too ill to be assessed before corrective surgery. The mean age of the group was 1.5 years (SD, 0.9 years; range, $0.2-3.4$ ). There were 10 girls. Eleven had cyanotic lesions and 14 had acyanotic lesions-these two subgroups will be referred to as the cyanotic and acyanotic groups, respectively. The mean ages of the two congenital heart disease subgroups were not significantly different (cyanotic group mean, 1.7 years; SD, 0.8; acyanotic group mean, 1.4 years; SD, 0.9). Follow up assessments were completed on 19 children; five died before the follow up assessment, and one was lost to follow up.

The transplant group comprised 15 children, of whom 14 had initial assessments. Follow up assessments were completed on eight children, the remaining seven dying before follow up. Fifteen healthy children were recruited and completed initial assessments, and 11 of these had follow up assessments (the remaining four being lost to follow up).

The groups did not differ significantly in their mean ages, sex distributions, or parents' socioeconomic status (table 1 ).

\section{MEASURES}

Children were assessed on admission for cardiac surgery or bone marrow transplantation, usually the day before surgery, and again 12 months later during a routine outpatient appointment, using the Ruth Griffiths Mental Development Scales. ${ }^{26}{ }^{27}$ For children younger than 2 years old there are five subscales: locomotor, personal/social, hearing/speech, eye-hand coordination, and performance. A sixth, the practical reasoning scale, is added from the third year onwards (this scale applied to only 16 children in the sample and is not reported in the results). Because, in common with other measures of development, the scales rely on parental reporting and focus more heavily on sensory motor function than tests for older age groups, their validity as a predictive measure of later IQ is questionable. ${ }^{28-30}$ Nevertheless, the features on which the scales focus are those considered pertinent to the development of preschool children and the scales have been used with chronically ill or handicapped children, ${ }^{31-33}$ and they are the most widely used infant development scale in the UK. ${ }^{34}$ In addition, on both test occasions, parents took part in a semi-structured interview that included questions about the child's behaviour.

\section{STATISTICAL ANALYSIS}

Developmental measures at each test occasion were compared by one way analysis of variance. Scheffe's multiple comparison tests were used to identify the source of any significant differences $(p<0.05)$ between the cardiac, transplant, and healthy groups, and between the cyanotic, acyanotic, transplant, and healthy groups. Performance of the cyanotic and acyanotic subgroups was compared using independent Student's $t$ tests. Within group changes over time in developmental function were assessed using paired Student's $t$ tests. Between group comparisons over time were assessed using repeated measures analysis of variance. Correlations of age and performance were measured using Pearson correlation coefficients.

\section{Results}

INITIAL ASSESSMENTS

Although all the mean subtest scores and overall IQ score for the cardiac subgroups and total cardiac, transplant, and healthy groups were within the normal range, ${ }^{27}$ both the cardiac and transplant groups obtained significantly lower scores on the locomotor, personal/social, and speech and hearing scales, together with the overall IQ score, compared with the healthy group (table 2). All of the individual scores were within the normal range with the exception of the locomotor scores, which were below the normal range in four children in the cardiac group and two children in the transplant group. There were no significant differences between the total congenital heart disease group and the bone marrow transplantation group, or within the cardiac group between the children with cyanotic and those with acyanotic lesions. Compared with the healthy group (table 2), both cardiac subgroups had significantly lower

Table 2 Initial mean (SE) development quotients and IQ

\begin{tabular}{|c|c|c|c|c|c|}
\hline \multirow[b]{2}{*}{ Scale } & \multicolumn{3}{|l|}{ Group } & \multirow{2}{*}{$\begin{array}{l}95 \% C I \text { (difference between } \\
C H D \text { and BMT groups) }\end{array}$} & \multirow{2}{*}{$\begin{array}{l}95 \% \text { CI (difference between } \\
\text { CHD and healthy groups) }\end{array}$} \\
\hline & $C H D$ & $B M T$ & Healthy & & \\
\hline Locomotor & $95(4)^{\star \star}$ & $100(6)^{\star}$ & $124(3)$ & -18.7 to 8.8 & -41.0 to -17.8 \\
\hline Personal/social & $104(2)^{\star \star}$ & $95(2)^{\star \star}$ & $122(4)$ & 2.4 to 16.4 & -26.1 to -8.7 \\
\hline Speech/hearing & $101(3)^{\star}$ & $97(5)^{\star}$ & $120(6)$ & -6.9 to 15.1 & -31.6 to -7.3 \\
\hline Eye-hand coordination & $102(2)$ & $103(4)$ & $112(4)$ & -8.2 to 6.3 & -18.2 to -1.6 \\
\hline Performance & $109(3)$ & $105(5)$ & $119(4)$ & -6.3 to 14.9 & -19.2 to 0.4 \\
\hline Overall IQ & $102(2)^{\star \star}$ & $100(3)^{\star \star}$ & 119 (3) & -3.8 to 8.4 & -23.7 to -10.4 \\
\hline
\end{tabular}

${ }^{\star} \mathrm{p}<0.01$ (cardiac and BMT groups compared with healthy group)

$\star \star \mathrm{p}<0.001$ (cardiac and BMT groups compared with healthy group).

$\mathrm{CHD}$, congenital heart disease; BMT, bone marrow transplantation; CI, confidence interval. 
Table 3 Postoperative mean (SE) development quotients and IQ

\begin{tabular}{|c|c|c|c|c|c|}
\hline \multirow[b]{2}{*}{ Scale } & \multicolumn{3}{|l|}{ Group } & \multirow{2}{*}{$\begin{array}{l}95 \% \mathrm{CI} \text { (difference between } \\
C H D \text { and BMT groups) }\end{array}$} & \multirow{2}{*}{$\begin{array}{l}95 \% C I \text { (difference between } \\
\text { CHD and healthy groups) }\end{array}$} \\
\hline & $C H D$ & $B M T$ & Healthy & & \\
\hline Locomotor & $98(4)^{\star}$ & $107(8)$ & $119(4)$ & -26.5 to 7.9 & -33.5 to -8.1 \\
\hline Personal/social & $100(5)^{\star}$ & $100(5)$ & $116(3)$ & -16.6 to 13.9 & -29.3 to -3.7 \\
\hline Speech/hearing & $100(6)$ & $101(6)$ & $119(6)$ & -20.9 to 19.4 & -37.2 to -1.3 \\
\hline Eye-hand coordination & $100(3)^{\star}$ & $103(5)$ & $115(4)$ & -13.9 to 8.9 & -25.4 to -4.2 \\
\hline Performance & $111(4)$ & $112(5)$ & $120(4)$ & -14.7 to 16.0 & -22.5 to 4.1 \\
\hline Overall IQ & $102(4)^{\star}$ & $104(5)$ & $117(4)$ & -16.3 to 11.1 & -26.9 to -3.8 \\
\hline
\end{tabular}

${ }^{\star} \mathrm{p}<0.05$ (CHD and healthy groups).

$\mathrm{CHD}$, congenital heart disease; BMT, bone marrow transplantation; $\mathrm{CI}$, confidence interval.

scores on the locomotor subscale (cyanotic mean (SE) developmental quotient (DQ), 92 (9); $95 \%$ confidence interval of the difference between cyanotic and healthy groups (CI), -48.4 to $-15.6 ; \mathrm{p}=0.001$; acyanotic mean (SE) DQ, 97 (4); 95\% CI, -37.2 to -17.8 ; $\mathrm{p}=0.001)$, and the personal/social subscale (cyanotic mean (SE) DQ, 106 (5); healthy mean (SE) DQ, 122 (4); 95\% CI, -28.7 to $-3.5 ; \mathrm{p}=0.015$; acyanotic mean (SE) DQ, 104 (3); $95 \% \mathrm{CI},-27.9$ to $-8.8 ; \mathrm{p}=0.001)$. Compared with the healthy group, the overall IQ was lower in both the cyanotic group (cyanotic mean (SE) IQ, 102 (3); 95\% CI, -26.6 to -7.4 ; $\mathrm{p}=0.001$ ) and the acyanotic group (acyanotic mean (SD) IQ, 102 (2); $95 \%$ CI, -24.9 to -9.4 ; $\mathrm{p}=0.001)$. Testing for negative correlations of the subscale scores with age in the two congenital heart disease subgroups, only one significant correlation was found, for eye-hand coordination in the cyanotic subgroup $(r=-0.71$; $\mathrm{p}=0.01)$.

FOLLOW UP ASSESSMENTS

Although the mean performance on all of the subtests was again within the normal range in the congenital heart disease group,${ }^{27}$ compared with the healthy group, the congenital heart disease group continued to show impaired locomotor and personal/social functioning, as well as lower overall IQ (table 3). Considering all of the individual tests, between one and three children in the cardiac group and one child in the BMT group had scores below the normal range. All individual scores for the healthy children were within the normal range. Although the poorer performance of the cardiac group at initial assessment on speech and hearing (table 2) was no longer significant at follow up (table 3), the congenital heart disease group showed poorer hand-eye coordination than the healthy group. The differences found at initial assessment between the BMT and healthy groups were no longer significant at follow up (table 3 ).

Table 4 summarises data for the cyanotic and acyanotic groups (note that table 4 includes data only from those children that were followed up successfully, and the preoperative test results in table 4 therefore differ slightly from those presented above for all the children assessed preoperatively). The differences at follow up between the cardiac group and the others were largely attributable to the children in the cyanotic group, with no significant differences being found between the acyanotic and healthy group scores. Compared with the healthy group (table 3), the cyanotic group showed impaired performance on the locomotor subscale (cyanotic mean DQ, 79; 95\% CI, -3.25 to $-25.17 ; \mathrm{p}=0.001)$, on personal/ social functioning (cyanotic mean DQ, 88; $95 \% \mathrm{CI},-42.0$ to $-14.2 ; \mathrm{p}=0.001)$, and on overall IQ (cyanotic mean IQ, 92; 95\% CI, -40.0 to $-10.6 ; \mathrm{p}=0.002)$. The cyanotic and acyanotic subgroups differed significantly on the locomotor subscale and the differences almost reached significance on the personal/ social subscale and on overall IQ (table 4). In the cyanotic group, performance on the eye-hand coordination and performance subscales was positively correlated with age at repair. In the acyanotic group there were no significant correlations between subscale scores and age.

CHANGES OVER TIME IN THE CONGENITAL HEART DISEASE GROUPS

In the acyanotic group, some subscales showed a trend to improvement postoperatively, although none of these changes were significant (table 4). In contrast, the cyanotic group showed significant deterioration in locomotor and personal/social functioning (table 4).

Table 4 Mean (SE) development quotients and IQ of the two congenital heart disease subgroups

\begin{tabular}{|c|c|c|c|c|c|c|c|c|}
\hline \multirow[b]{2}{*}{ Score } & \multicolumn{2}{|l|}{ Cyanotic } & \multicolumn{2}{|c|}{ Acyanotic } & \multirow{2}{*}{$\begin{array}{l}95 \% \text { CI (differences } \\
\text { between preoperative } \\
\text { and postoperative } \\
\text { cyanotic scores) }\end{array}$} & \multirow{2}{*}{$\begin{array}{l}95 \% \text { CI (differences } \\
\text { between preoperative } \\
\text { and postoperative } \\
\text { acyanotic scores) }\end{array}$} & \multirow{2}{*}{$\begin{array}{l}95 \% \text { CI (differences } \\
\text { between preoperative } \\
\text { cyanotic and } \\
\text { acyanotic scores) }\end{array}$} & \multirow{2}{*}{$\begin{array}{l}95 \% \text { CI (differences } \\
\text { between postoperative } \\
\text { cyanotic and acyanoti } \\
\text { scores) }\end{array}$} \\
\hline & Pre & Post & Pre & Post & & & & \\
\hline Locomotor & $104(5) \dagger$ & $79(6)^{\star} \dagger$ & 99 (3) & $107(3)^{\star}$ & 8.8 to 40.2 & -15.6 to 0.3 & -8.3 to 17.5 & -41.4 to -13.8 \\
\hline Personal/social & $103(7) \ddagger$ & $88(7) \ddagger$ & $105(3)$ & $106(5)$ & 4.6 to 25.4 & -10.9 to 9.5 & -15.2 to 11.7 & -36.1 to 1.2 \\
\hline Speech/hearing & $97(7)^{\top}$ & $93(10)$ & $103(4)$ & $104(7)$ & -20.2 to 28.9 & -10.8 to 9.0 & -21.1 to 10.3 & -36.0 to 14.7 \\
\hline \multicolumn{9}{|l|}{ Eye-hand } \\
\hline coordination & $100(5)$ & $96(7)$ & $102(2)$ & $102(3)$ & -23.1 to 30.8 & -6.7 to 6.4 & -12.1 to 7.6 & -19.8 to 7.3 \\
\hline Performance & $117(6)$ & $103(8)$ & $109(4)$ & $115(5)$ & -12.5 to 41.5 & -15.5 to 4.8 & -7.3 to 23.1 & -31.0 to 7.1 \\
\hline Overall IQ & $104(4)$ & $92(7)$ & $104(2)$ & $107(4)$ & -3.0 to 27.7 & -9.4 to 3.7 & -8.1 to 8.8 & -30.5 to 0.9 \\
\hline
\end{tabular}

These figures are derived exclusively from children who completed both assessments, and the preoperative data differ slightly from those given in the text, which include all children who completed the initial assessment.

${ }^{\star} \mathrm{p}=0.001 ; \mathrm{t} \mathrm{p}=0.010 ; \neq \mathrm{p}=0.014$ ( $\mathrm{p}$ values for "cyanotic post" are for pre and post cyanotic scores, and post acyanotic and cyanotic scores)

$\mathrm{CI}$, confidence interval. 
PARENTAL INTERVIEWS

Dependency and inactivity were the two main areas of concern mentioned by parents preoperatively. Paradoxically, a number of mothers also reported that their own anxiety resulted in them overprotecting their children, preventing them becoming more independent. After surgery, three mothers of children with cyanotic lesions specifically mentioned that their children were very clingy and did not mix with other children. Again, maternal anxiety appeared to be a major factor in these behaviour patterns. In contrast, mothers of children with acyanotic lesions did not report dependency to be a problem after surgery; correspondingly, their own level of anxiety was reduced from preoperative levels.

CHILDREN WITH CONGENITAL HEART DISEASE

NOT FOLLOWED UP

Five of the six children who were not followed up died; the remaining child was lost to follow up. Comparison of the follow up sample and those who died indicated that the two samples differed significantly only on the locomotor scale, with those children who died obtaining a lower score $(t=3.06 ; p=0.006)$.

\section{Discussion}

Our study is the first prospective investigation of the effects of corrective surgery on cognitive and developmental functioning in younger children with congenital heart disease. Apart from its prospective design, one of the main strengths of our study was the inclusion of two comparison groups. Comparing the cardiac group with another group of children undergoing bone marrow transplantation allowed some discrimination between the effects of chronic illness in general and congenital heart disease in particular. Although both groups showed preoperative scores in the normal range on the Ruth Griffiths scales, comparisons between these groups and the healthy control children were more revealing. On both test occasions, the healthy group achieved higher scores than would be expected from the standardised norms for the tests. ${ }^{26}{ }^{27}$ The most likely explanation for this is that the standardised norms for the tests are no longer appropriate. A study of 447 infants tested from 1978 to 1982 using the same scales found a significantly higher DQ than that originally suggested. ${ }^{30}$

Our study also has limitations that must be borne in mind when interpreting the results. In particular, the sample is relatively small, especially when considering comparisons between the cyanotic and acyanotic subgroups. Thus, some of the findings might be liable to type II statistical errors. Nevertheless, the way in which the sample was selected should ensure that the children studied were largely representative of those with congenital heart disease coming to corrective surgery, although children with appreciable learning disabilities were excluded.

The hypotheses tested were derived mainly from work involving older children. Our results provide only limited support for these hypotheses. The results indicate that, relative to their healthy peers, young children with congenital heart disease do indeed demonstrate cognitive and developmental impairment but that the cardiac and bone marrow transplantation groups did not differ. Our data fail to support the hypotheses that compared with children with acyanotic lesions, those with cyanotic lesions would show greater cognitive and developmental impairment preoperatively, and greater improvement after surgery. In addition, contrary to our predictions, the cyanotic group did not show any negative correlations between cognitive ability and age at surgery, except for eye-hand coordination. Although the two cardiac subgroups did not differ significantly overall from the healthy group in eye-hand coordination at initial assessment, overall, the cardiac group had lower scores than the healthy group on hand-eye coordination at follow up (table 3). If this effect was caused predominantly by children with cyanotic lesions and was associated with age at surgical repair, the failure to find differences between the cyanotic and acyanotic subgroups (table 4 ) could be explained by a type II statistical error.

The initial assessments failed to show any significant differences between the cardiac and transplant groups, but children in each of these groups showed poorer cognitive performance than their healthy peers, in keeping with previous research involving children with congenital heart disease. ${ }^{62}$ This supports other findings of compromised development attributable to chronic illness per se, ${ }^{1-43536}$ with gross motor and language development being affected particularly. ${ }^{14}{ }^{37}$ The impact on development of chronic illness in general, rather than specific diagnoses, is further supported by the failure to find differences preoperatively between children with cyanotic lesions and those with acyanotic lesions. Although this is contrary to previous findings, ${ }^{13}{ }^{16}$ these have focused on older children rather than the preschool age children investigated in our study.

Developmental delay in young children with chronic illness is expected to be multifactorial in origin. Even if the nature of the child's illness has relatively little direct effect on the extent of developmental delay, it is likely to influence potential aetiological factors. Four particular factors are likely to be important in explaining our results. First, children with cardiac disease are often physically less able to interact with their environment because of the limiting nature of their condition. The tests used depend to a significant extent on physical activity. Impaired physical abilities also hinder the development of other skills, such as exploratory behaviour. Second, maternal overprotectiveness is likely to be important. ${ }^{38-40} \mathrm{~A}$ number of mothers admitted keeping their children away from others (for example, because of fear of infection), thus limiting their child's social interactions. This is likely to influence the development of speech and socialisation skills particularly, consistent with our finding that the children with congenital heart disease performed significantly less well than their healthy peers on the personal/social and speech and hearing scales. Third, the 
effects of prolonged illness and hospitalisation are likely to be important. Some children in the cardiac group had spent prolonged periods of time in hospital, resulting in inconsistency of the physical environment and the number of people involved with the child, which could further have compromised their development. Fourth, feeding difficulties, particularly in the infants, may also have made parents feel inadequate and could cause them to withdraw emotional support from their infant, ${ }^{41-43}$ thus contributing to developmental delays.

Several factors might have contributed to the findings of a deterioration in performance in the cyanotic group after surgery. Six children with cyanotic lesions had been re-hospitalised since surgery, compared with none in the acyanotic group. Hospitalisation, particularly between the ages of 6 months and 4 years, is acknowledged to be potentially harmful emotionally, ${ }^{44}{ }^{45}$ and is also likely to compromise cognitive development. Furthermore, a number of the children had to undergo further procedures under general anaesthesia. Increasing numbers of procedures under general anaesthesia and periods of hospitalisation have been associated with adverse effects on the cognitive development of preschool age children. ${ }^{33}$ Although the cyanotic group did not show a loss of skills over time, they did not achieve the improved rate of development expected in one year. Poor developmental outcome after surgery in infancy has also been linked to a number of family variables, such as socioeconomic status. ${ }^{13}$ Maternal overprotection is also particularly relevant for the cyanotic group, with mothers of three of the six cyanotic patients in the younger age group specifically mentioning that their children were very dependent and clingy and that they did not mix with other children. From the interviews, it was apparent that these mothers were themselves anxious and unwilling to allow their children to be more active and engage in more exploratory behaviour. In contrast, the greater improvement noted by parents in physical condition in the acyanotic patients might have resulted in decreased parental overprotectiveness and a greater willingness to allow their child to develop appropriately.

Our results, in common with another recent study, ${ }^{46}$ failed to confirm the reported association in children with cyanotic lesions between age at time of repair and subsequent cognitive functioning. ${ }^{13} 1425$ The studies that have found this association have been based on children with the specific condition of transposition of the great arteries. Our sample was more heterogeneous and confined to younger children whose ages spanned a smaller range. The age range in our study may not have been great enough to expect any association between age at repair and subsequent cognitive function. Equally, such an association might be more evident in some specific cardiac conditions than others.

Our findings highlight the complex effects of chronic illness on the development of young children. Preoperatively, the predominant factor influencing cognitive and developmental delay appears to be chronic illness in general, with no significant differences identified between children with cyanotic or acyanotic heart lesions or those requiring bone marrow transplantation. However, 12 months after corrective intervention, clear differences are apparent between these three diagnostic groups. For children with acyanotic lesions successfully repaired in infancy, the prognosis is good for further cognitive and developmental progress. However, for those with cyanotic lesions, cognitive and developmental delays are more likely to be prolonged. Outcome after surgery is complex in its determination. Factors related to aspects such as parenting have been implicated in the continuing delayed development found in other groups of children one year after corrective surgery, supporting a multifactorial approach to the study of outcome in chronically sick children. ${ }^{47}$

Longer term follow up is now required to determine the extent to which young children with cyanotic lesions who show deficits in the preschool years remain at risk for cognitive delay. Future research also needs to identify any specific risk factors, which in turn will serve to inform appropriate psychosocial interventions as components of the comprehensive management of children with cardiac disease.

This work was funded by the Garfield Weston Trust, the Cancer Research Cas funded by the Garfield Weston Trust, the Cancer the Lord Ashdown Charitable Settlement. The cooperation of Professor H Zeitlin and Dr C Pot-Mees, formerly of WestminProfessor H Zeitlin and Dr C Pot-Mees, formerly of Westmin-
ster Children's Hospital, during the stage of data collection is ster Children's Hospital,
gratefully acknowledged.

1 Ack M, Miller I, Weil WB. Intelligence of children with diabetes mellitus. Pediatrics 1961;28:764-70.

2 Dikmen S, Matthews CG, Harley JP. The effect of early versus late onset of major motor epilepsy upon cognitiveintellectual performance. Epilepsia 1975;16:73-81.

3 Eiser C, Lansdown R. Retrospective study of intellectual development in children treated for acute lymphoblastic leukaemia. Arch Dis Child 1977;52:525-9.

4 Eiser C. Psychological sequelae of brain tumours in childhood: a retrospective study. Br f Clin Psychol 1981;20: 35-8.

5 Stewart SM, Uauy R, Kennard BD, Waller DA, Benser M, Andrews WS. Mental development and growth in children with chronic liver disease of early and late onset. Pediatrics 1988;82:167-72.

6 Aisenberg RB, Rosenthal A, Nadas AS, Wolff PH. Developmental delay in infants with congenital heart diseasecorrelation with hypoxemia and congestive heart failure. Pediatr Cardiol 1982;3:133-7.

7 Samango-Sprouse C, Suddaby EC. Developmental concerns in children with congenital heart disease. Curr Opin Cardiol 1997;12:91-8.

8 Aisenberg RB, Rosenthal A, Wolff PH, Nadas AS Hypoxemia and critical flicker frequency in congenital heart disease. Am $\mathcal{F}$ Dis Child 1974;128:335-8.

9 Bret J, Kohler C. Incidences neuropsychiatriques des cardiopathies congenitales chez l'enfant. Pediatrie 1956;11: 59-68.

10 Feldt RH, Ewert JC, Stickler GB, Weidman WH. Children with congenital heart disease: motor development and with congenital heart disease: motor developr

11 Silbert A, Wolff PH, Mayer B, Rosenthal A, Nadas AS. Cyanotic heart disease and psychological development. Pediatrics 1969;43:192-200.

12 Gonzalez-Pardo L, Miles M, Taylor M, Mattioli L. Congenital heart disease: developmental and neurological evaluation in preschool children. Fournal of the Kansas Medical Society 1981;82:115-18.

13 O'Dougherty M, Wright FS, Garmezy N, Loewenson RB, Torres F. Later competence and adaptation in infants who survive severe heart defects. Child Dev 1983;54:1129-42.

14 Newburger JW, Silbert AR, Buckley LP, Fyler DC. Cognitive function and age at repair of transposition of the great arteries in children. N Engl f Med 1984;310:1495-9.

15 Aram DM, Ekelman BL, Ben-Shachar G, Levinsohn MW. Intelligence and hypoxemia in children with congenital heart disease: fact or artifact? $f \mathrm{Am}$ Coll Cardiol 1985;6:889-93.

16 DeMaso DR, Beardslee WR, Silbert AR, Fyler DC. Psychological functioning in children with cyanotic heart defects. $\mathcal{F}$ Dev Behav Pediatr 1990;11:289-94. 
17 Stoch MB, Smythe PM. Does undernutrition during infancy inhibit brain growth and subsequent intellectual development? Arch Dis Child 1963;38:546-52.

18 Cravioto J, De Licardie E. Mental performance in school age children: findings after recovery from early severe malnutrition. Am f Dis Child 1970;120:404-10.

19 Galler JR, Ramsey F, Solimano G. The influence of early malnutrition on subsequent behavioural development: 1 . degree of impairment in intellectual performance. $\mathcal{F} A m$ Acad Child Psychiatry 1983;22:1-8.

20 Singer LT, Fagan JF. Cognitive development in the failureto-thrive infant: a three-year longitudinal study. F Pediat Psychol 1984;9:363-83.

21 Meyendorf R, Jansch G, Trondle C, Takke E, Buhlmeyer K, Sebening F. Psychiatric complications in children after heart surgery: a pre- and postoperative comparison of 4- to 13-year-olds. Z Kinder fugenpsychiatr 1980;8:395-406.

22 Linde LM, Rasof B, Dunn OJ. Longitudinal studies of intellectual and behavioral development in children with conlectual and behavioral development in children with con-

23 genital heart disease. Acta Paediatr Scand 1970;59:169-76. of the great vessels. Arch Dis Child 1988;63:198-200.

24 Mendoza JC, Wilkerson SA, Reese AH. Follow-up of patients who underwent arterial switch repair for transposition of the great arteries. Am f Dis Child 1991;145:40-3.

25 Newburger JW, Tucker AD, Silbert AR, Fyler DC. Moto function and timing of surgery in transposition of the great arteries, intact ventricular septum [abstract]. Pediatr Cardiol 1983;4:317

26 Griffiths R. The abilities of babies: a study in mental measurement. Thetford, Norfolk: Lowe \& Brydone Ltd, 1954.

27 Griffiths R. The abilities of young children: a comprehensive system of mental measurement for the first eight years of life. London: Child Development Research Centre, 1970.

28 Rasof B, Linde LM, Dunn OJ. Intellectual development in children with congenital heart disease. Child Dev 1967;38: 1043-53.

29 Aldridge Smith J, Bidder RT, Gardner SM, Gray OP. Griffiths scales of mental development and different users. fiths scales of mental development
Child Care Health Dev 1980;6:11-16.

30 Hanson R, Aldridge-Smith J, Hume W. Achievements of infants on items of the Griffiths scales: 1980 compared with 1950. Child Care Health Dev 1985;11:91-104

31 Bidder RT, Bryant G, Gray OP. Benefits to Down's syndrome children through training their mothers. Arch Dis Child 1975;50:383-6.

32 Balestrini MR, Zanette M, Micheli R, Fornari M, Solero CL, Broggi G. Hemispheric cerebral tumors in children: long-term prognosis concerning survival rate and quality of life-considerations on a series of 64 cases operated upon. Childs Nerv Syst 1990;6:143-7.
33 Ludman L, Spitz L, Lansdown R. Intellectual development at 3 years of age of children who underwent major neonatal surgery. F Pediatr Surg 1993;28:130-4.

34 Tyler B, Miller K. The use of tests by psychologists: report on a survey of BPS members. Bulletin of the British Psychological Society 1986;39:405-10.

35 So SKS, Chang PN, Najarian IS, Mauer SM, Simmons RL, Nevins TE. Growth and development in infants after renal transplantation. F Pediatr 1987;110:343-50.

36 Stewart SM, Uauy R, Waller DA, Kennard BD, Andrews WS. Mental and motor development correlates in patients with end-stage biliary atresia awaiting liver transplantation. Pediatrics 1987;79:882-8.

37 Polinsky MS, Kaiser BA, Stover JB, Frankenfield M, Baluarte HJ. Neurologic development of children with severe chronic renal failure from infancy. Pediatr Nephrol 1987;1:157-65.

38 Landtman B, Valanne E, Pentti R, Aukee M. Psychosomatic behaviour of children with congenital heart disease. Preand post-operative studies of eighty-four cases. Annals Paediatriae Fenniae 1960;6(suppl 15):3-78.

39 Linde LM, Rasof B, Dunn OJ, Rabb E. Attitudinal factors in congenital heart disease. Pediatrics 1966;38:92-101.

40 Offord DR, Cross LA, Andrews EJ, Aponte JF. Perceived and actual severity of congenital heart disease and effect on family life. Psychosomatics 1972;13:390-6.

41 Gudermuth S. Mothers' reports of early experiences of infants with congenital heart disease. Matern Child Nurs 7 1975;4:155-64

42 D'Antonio IJ. Mothers' responses to the functioning and behavior of cardiac children in child-rearing situations. Matern Child Nurs f 1976;5:206-59.

43 Shor VS. Long-term implications of cardiovascular disease. Issues in Comprehensive Pediatric Nursing 1978;2:36-50.

44 Prugh DG, Staub EM, Sands HH, Kirschbaum RM, Lenihan EA. A study of the emotional reactions of children and families to hospitalization and illness. Am f Orthopsychiatry 1953;23:70-106

45 Vernon DTA, Schulman JL, Foley JM. Changes in children's behavior after hospitalisation. Am f Dis Child 1966;3:581-93.

46 Oates RK, Simpson JM, Cartmill TB, Turnbull JAB. Intellectual function and age of repair in cyanotic congenital heart disease. Arch Dis Child 1995;72:298-301.

47 Stewart SM, Uauy R, Waller DA, Kennard BD, Benser M, Andrews WS. Mental and motor development, social competence and growth one year after successful pediatric liver transplantation. F Pediatr 1989;114:574-81. 